\title{
Dynamically Stabilize and Balance Air Flow of the Dust-Removal System
}

$$
\text { Qiuxin Liu', A, Neng Wang',B And Fen Chen }{ }^{3, C}
$$

${ }^{1}$ College of Urban Construction, Wuhan University of Science and Technology, Wuhan, China

${ }^{2}$ College of Urban Construction, Wuhan University of Science and Technology, Wuhan, China

${ }^{3}$ College of Urban Construction, Wuhan University of Science and Technology, Wuhan, China

a18771094025@163.com, b614966770@qq.com, ‘894034012@qq.com

Keywords: Adjustable wear-resistant orifice plate; Adjust performance; Wear resistance; The adaptive fuzzy pid control.

Abstract. Through the experimental test and $c f d$ numerical simulation of the new valve body of the adjustable wearable orifice plate, it is proved that the orifice plate has good stability and regulating performance for the air volume of the dust-removal system under different pressure fluctuations. In view of the wear properties of the orifice plate, it is suggested that the wear resistance of the valve body can be effectively improved by the use of wear-resistant ceramics on windward side. And the Simulink simulation of the control system shows that the adjustable wear-resistant orifice plate adopting the adaptive fuzzy pid control can adapt well to the unstable characteristics of the dust removal system.

\section{Introduction}

With a boom of modern industry and the increasing requirements of environmental protection, the ventilating and dust-removal system is increasingly marvelous and complex. Thus the system's resistance unbalance and many problems, such as dust accumulation, blockage and local component wear in the course of the operation, are also highlighted [1]. Subsequently resulting in the entire system operation process of air volume deviate from the design values and the dust removal effect can't be guaranteed. Therefore, it is an important research that study how to realize the hydraulic balance of dust removal system and solve the problem of air volume imbalance caused by the dynamic fluctuation of pressure in the operation of the network.

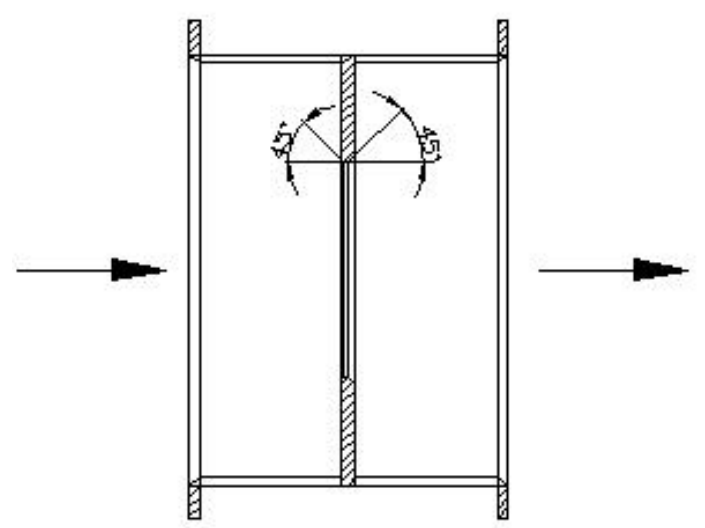

Fig. 1. Structure diagram of the wear-resistant orifice plate

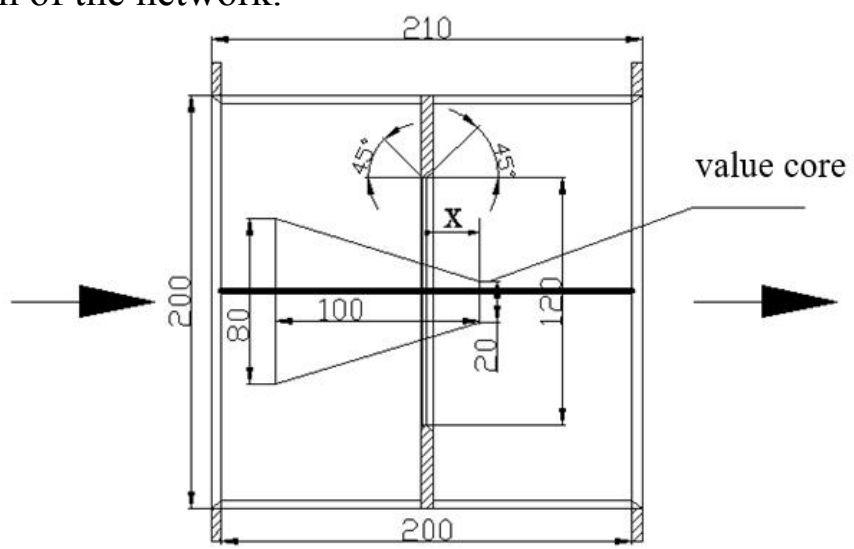

Fig. 2. Structure diagram of the adjustable wear-resistant orifice plate

With referring to the structure and characteristics of valve parts that exist in the dust-removal system, it is putting forward the adjustable wear-resistant orifice plate. Fig. 1 is the structure diagram of the wear-resistant, and Fig. 2 is the structure diagram of the adjustable orifice plate wear-resistant orifice plate. The regulation and resistance properties of the valve structure can be obtained through several experiments for all conditions of it. Based on the above conclusion, the numerical model of the adjustable wear-resistant orifice plate is established. With its simulated result, the experimental result can be verified, the wear resistance of the wear-resistant ceramic valves and the wear resistance of the wear-resistant steel plate valves can be obtained. Finally, simulink 
simulation is used to analyze and compare the conventional pid control and the adaptive fuzzy pid control, which is of great significance to eliminate the Resistance disorder the instability of air flow caused by pressure fluctuation.

\section{The Experiment of the Adjustable Wear-Resistant Orifice Plate}

Fig. 3 is the experimental system, being used to test the performance of the adaptive fuzzy pid control under different fluctuations of pressure. The pressure fluctuation in the dust-removal system is simulated by shifting the displacement of the regulating valve.

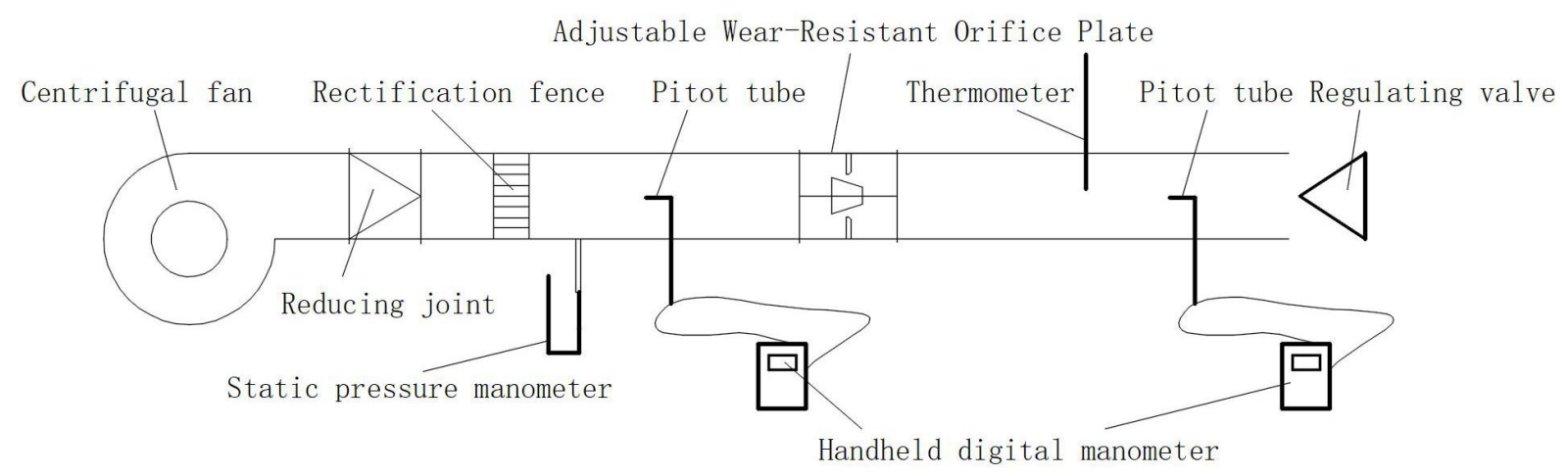

Fig. 3. Schematic diagram of the experimental station of the dust-removal system

The regulating performance test of the adjustable wear-resistant orifice plate

Table 1 and Table 2 are the results of the dust-removal system's air volume adjustment, which uses the adjustable wear-resistant orifice plate under the condition of different pressure fluctuations. The initial positions of the spool are $0.10 \mathrm{~m}$ and $0.06 \mathrm{~m}$.

From Table 1 and Table 2, it is showing that the system's air volume gets great deviations at the initial position of $\mathrm{x}_{0}=0.10 \mathrm{~m}$ and $\mathrm{x}_{0}=0.06 \mathrm{~m}$ for the spool, while the system's pressure fluctuation is greater than 500pa and 300pa. This is because the valve has been adjusted to a final position and the system's pressure fluctuation has exceeded the maximum range of the valve, then the valve can't be achieved control of the air system. And for the regulation of different working conditions while the scope of the system's pressure fluctuation is less than 500pa and 300pa, the body can ensure the system volume deviation within $2 \%$, it is showing that the regulating performance of the value is excellent.

Table 1 The test results of the system's air volume under different pressure fluctuations at $\mathrm{x}_{0}=0.1 \mathrm{~m}$

\begin{tabular}{|c|c|c|c|c|c|c|c|c|}
\hline $\begin{array}{c}\text { system's } \\
\text { pressure } \\
\begin{array}{c}\text { fluctuation } \\
(\mathrm{pa})\end{array}\end{array}$ & $\begin{array}{c}\text { value's } \\
\text { pressure } \\
\text { drop } \\
(\mathrm{pa})\end{array}$ & $\begin{array}{c}\text { value's } \\
\text { inlet } \\
\text { mean } \\
\text { dynamic } \\
\text { pressure } \\
(\mathrm{pa})\end{array}$ & $\begin{array}{c}\text { value's } \\
\text { inlet air } \\
\text { volume } \\
\left(\mathrm{m}^{3} / \mathrm{h}\right)\end{array}$ & $\begin{array}{c}\text { value's } \\
\text { outlet } \\
\text { mean } \\
\text { dynamic } \\
\text { pressure } \\
(\mathrm{pa})\end{array}$ & $\begin{array}{c}\text { value's } \\
\text { outlet } \\
\text { air } \\
\text { volume } \\
\left(\mathrm{m}^{3} / \mathrm{h}\right)\end{array}$ & $\begin{array}{c}\text { leak } \\
\text { out } \\
\text { rate } \\
(\%)\end{array}$ & $\begin{array}{c}\text { deviation } \\
\text { of air } \\
\text { volume } \\
(\%)\end{array}$ & $\begin{array}{c}\text { spool } \\
\text { position } \\
(\mathrm{m})\end{array}$ \\
\hline 0 & 813 & 40.2 & 926 & 40 & 920 & 0.61 & 0.00 & 0.1 \\
\hline 100 & 716 & 40.0 & 924 & 39 & 914 & 0.98 & -0.61 & 0.071 \\
\hline 200 & 611 & 40.4 & 928 & 39 & 917 & 1.22 & -0.37 & 0.035 \\
\hline 300 & 521 & 40.0 & 922 & 39 & 913 & 0.98 & -0.74 & 0.008 \\
\hline 350 & 485 & 38.2 & 902 & 38 & 896 & 0.63 & -2.58 & 0 \\
\hline 500 & 321 & 25.3 & 734 & 25 & 726 & 1.08 & -21.13 & 0 \\
\hline 600 & 229 & 18.0 & 619 & 18 & 615 & 0.73 & -33.17 & 0 \\
\hline
\end{tabular}


Table 2 The test results of the system's air volume under different pressure fluctuations at $\mathrm{x}_{0}=0.06 \mathrm{~m}$

\begin{tabular}{|c|c|c|c|c|c|c|c|c|}
\hline $\begin{array}{c}\text { system's } \\
\text { pressure } \\
\text { fluctuation } \\
(\mathrm{pa})\end{array}$ & $\begin{array}{c}\text { value's } \\
\text { pressure } \\
\text { drop } \\
(\mathrm{pa})\end{array}$ & $\begin{array}{c}\text { value's } \\
\text { inlet } \\
\text { mean } \\
\text { dynamic } \\
\text { pressure } \\
(\mathrm{pa})\end{array}$ & $\begin{array}{c}\text { value's } \\
\text { inlet air } \\
\text { volume } \\
\left(\mathrm{m}^{3} / \mathrm{h}\right)\end{array}$ & $\begin{array}{c}\text { value's } \\
\text { outlet } \\
\text { mean } \\
\text { dynamic } \\
\text { pressure } \\
(\mathrm{pa})\end{array}$ & $\begin{array}{c}\text { value's } \\
\text { outlet } \\
\text { air } \\
\text { volume } \\
\left(\mathrm{m}^{3} / \mathrm{h}\right)\end{array}$ & $\begin{array}{c}\text { leak } \\
\text { out } \\
\text { rate } \\
(\%)\end{array}$ & $\begin{array}{c}\text { deviation } \\
\text { of air } \\
\text { volume } \\
(\%)\end{array}$ & $\begin{array}{c}\text { spool } \\
\text { position } \\
(\mathrm{m})\end{array}$ \\
\hline 0 & 795 & 46.8 & 998 & 46 & 988 & 1.02 & 0.00 & 0.06 \\
\hline 100 & 704 & 46.4 & 994 & 46 & 985 & 0.91 & -0.34 & 0.036 \\
\hline 200 & 593 & 45.6 & 986 & 44 & 977 & 0.92 & -1.14 & 0.007 \\
\hline 200 & 597 & 47.0 & 1000 & 46 & 992 & 0.79 & 0.46 & 0 \\
\hline 300 & 521 & 41.2 & 937 & 40 & 924 & 1.45 & -6.52 & 0 \\
\hline 500 & 303 & 23.7 & 711 & 23 & 699 & 1.75 & -29.29 & 0 \\
\hline
\end{tabular}

The regulating performance test of the adjustable wear-resistant orifice plate

Fig. 4 shows the testing results of the local resistance coefficients of the valve body at different wind speeds, while the initial position of the valve core are $\mathrm{x}_{0}=0.00 \mathrm{~m}, \mathrm{x}_{0}=0.05 \mathrm{~m}$ and $\mathrm{x}_{0}=0.10 \mathrm{~m}$.

From Fig. 4, it can be seen that if the valve is in a fixed position, the local resistance coefficient of the value almost keeps in a certain value and the fluctuation is very small when altering the fluid velocity, since there is always with the experimental error. The local resistance coefficient of the value does not change with the change of the air velocity in the pipeline and it is a physical property of the body itself. The property of the adjustable wear-resisting orifice plate reveals that if the system's air volume is within the adjustable range of the valve body, the valve body can be used for any dust-removal system and the resistance characteristics of the valve body does not need to be calculated.

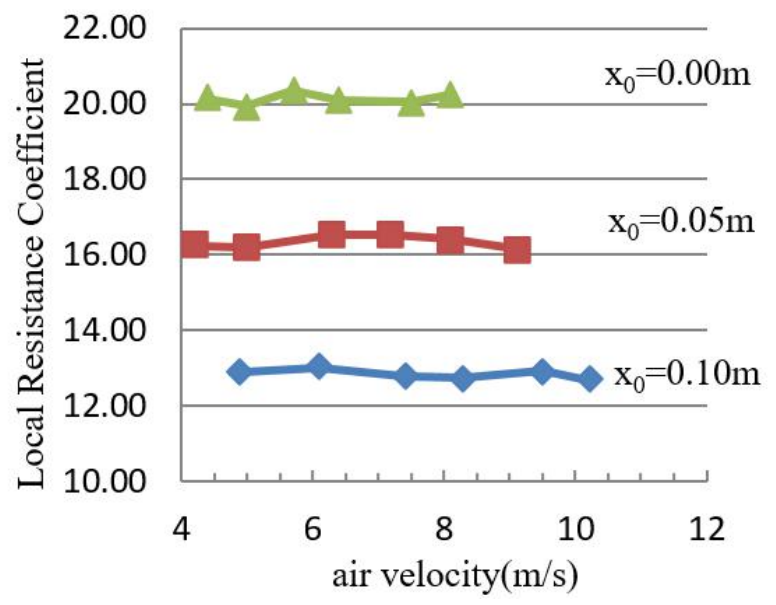

Fig. 4. The local resistance coefficient of the value under different air velocity (the experiment) 


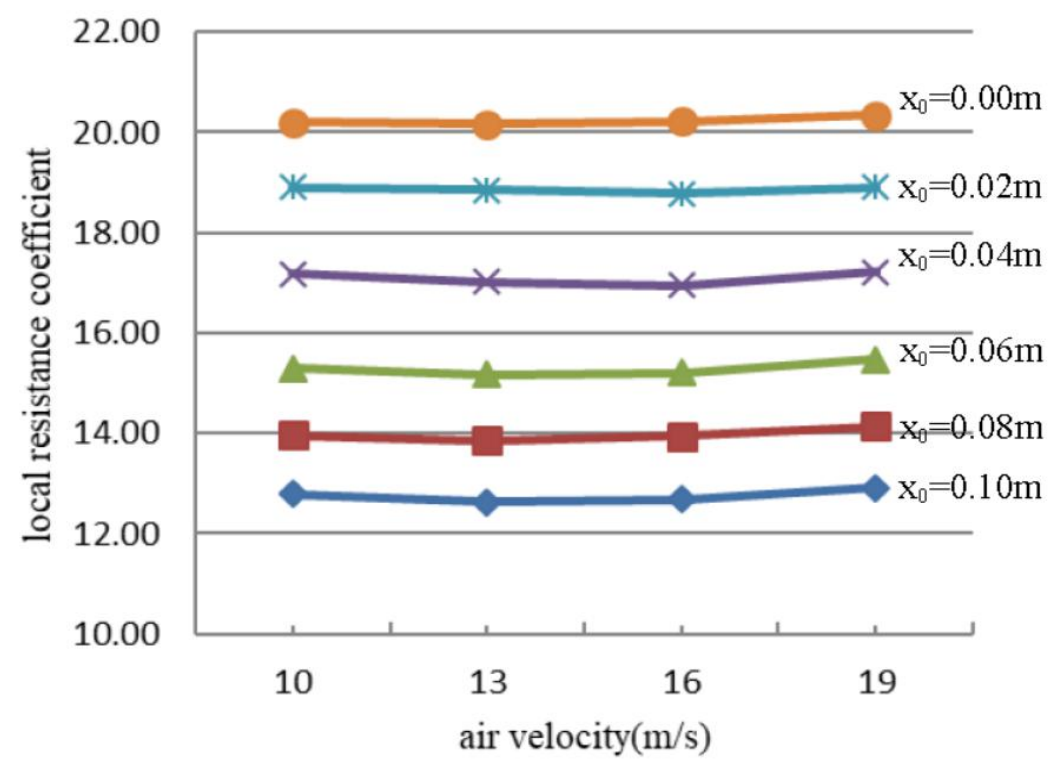

Fig. 5. The local resistance coefficient of the value under different air velocity (the simulation)

\section{The Simulation Analysis of Resistance Characteristics About the Adjustable Wear-Resistant Orifice Plate}

In the $c f d$ simulation software, the inlet air velocity of the adjustable wear-resisting orifice is changed, and the simulation result of the local resistance coefficient under different spool positions can be shown in Fig. 5. From this figure, if the valve is located in a certain position, the local resistance coefficient of the value will not change with the change of wind speed in the pipeline. The slight fluctuation is on account of the error in the simulation calculation and the accuracy chose. As a result, the local resistance coefficient is the property of the value and does not change with the change of the wind speed in the pipe. It is related to the structural parameters of the adjustable wear-resisting orifice plate rather than the air velocity.

Having the datum on Table 1, Table 2 and Fig. 5, regression analysis and data fitting of the experimental data and simulated data of the local resistance coefficient of the valve body at different wind speeds to get Fig. 6.

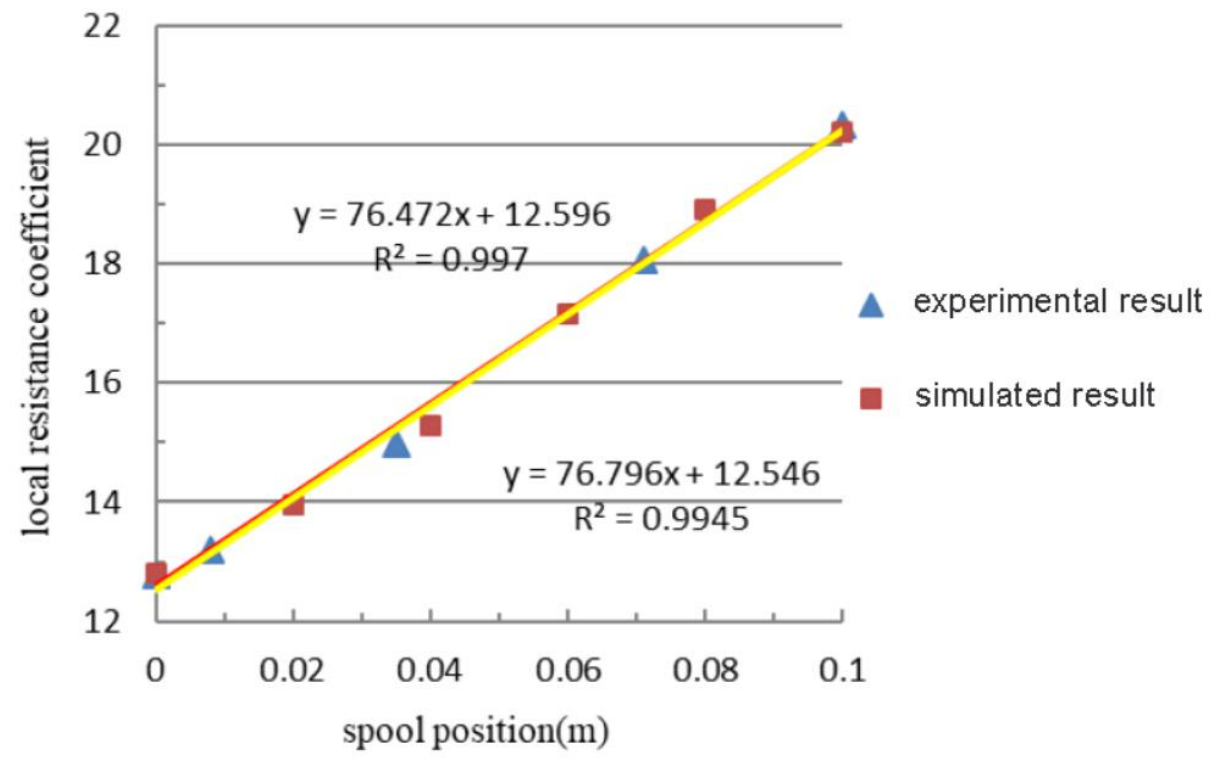

Fig. 6. The fitting curve of the local resistance coefficient and the value 
From Fig. 6, the fitting curve of the experimental result and the fitting curve of the simulation result nearly coincide, the local resistance coefficient is linearly proportional to the valve spool's position. It is intuitive to show the consistency of experiment and simulation results and demonstrates the accuracy of experiment and simulation. Further, the relationship between the resistance coefficient and the spool position, while an adjustable wear-resistant orifice plate is with an aperture of $120 \mathrm{~mm}$, a top circle diameter of $20 \mathrm{~mm}$, a height of $100 \mathrm{~mm}$ and a bottom diameter of $80 \mathrm{~mm}$, is $\mathrm{y}=76.915 \mathrm{x}+12.518$.

\section{The Simulation Analysis of Wear Properties about the Adjustable Wear-Resistant Orifice Plate}

According to the characteristics of the $d p m$ wear model in $c f d$ simulation software, the model of the erosion mechanism which is proposed by Tulsa University scholar is used in the study [2]. It is considering the solid particle's size, the striking velocity of the solid particle, the wall angle when the solid particle hit the wall, the effect of the solid particle concentration on the wall erosion and the influence of the wall's material on erosion wear.

$$
R_{\text {erosion }}=\frac{C m_{P}(H B)^{-0.59} F_{P} v^{n} f(\alpha)}{A_{\text {face }}}
$$

Where $R_{\text {erosion }}$ is the abrasion rate of wall materials; $C$ is the constant for wall materials: $m_{p}$ is the mass flow of solid particles; $H B$ is the Brinell Hardness of wall materials; $F_{P}$ is the shape factor of solid particles; $v^{n}$ is the impact velocity of solid particle; $f(\alpha)$ is the impact angle function; $A_{\text {face }}$ is the area of the calculation unit.

The simulation analysis of wear properties about the wear-resistant steel plate valve

From Fig. 7 and Fig. 8, they show that the abrasion of the valve at upwind side which is in the end face of the hole plate and the end face of the valve core's top circle is more serious than that are in the end face of the hole plate, the end face of the valve core's bottom circle and side face. The maximum abrasion quantity at windward side is in the edge of the hole plate and it is $7.77 \times 107 \mathrm{~kg} / \mathrm{m} 2 \cdot \mathrm{s}-1$, since the flow section abruptly narrows, the velocity of the solid particle increases and the impact angle is within the range of $20 \sim 30^{\circ}$ while the inner wall wear will have the most serious [3]. The maximum abrasion quantity at leeward side is in the side of the circle on the bottom of the spool and it is $2.40 \times 106 \mathrm{~kg} / \mathrm{m} 2 \cdot \mathrm{s}-1$, the impact angle gradually increases to $20 \sim 30^{\circ}$ even if the velocity of solid particle reduces, so the wear extent increases.
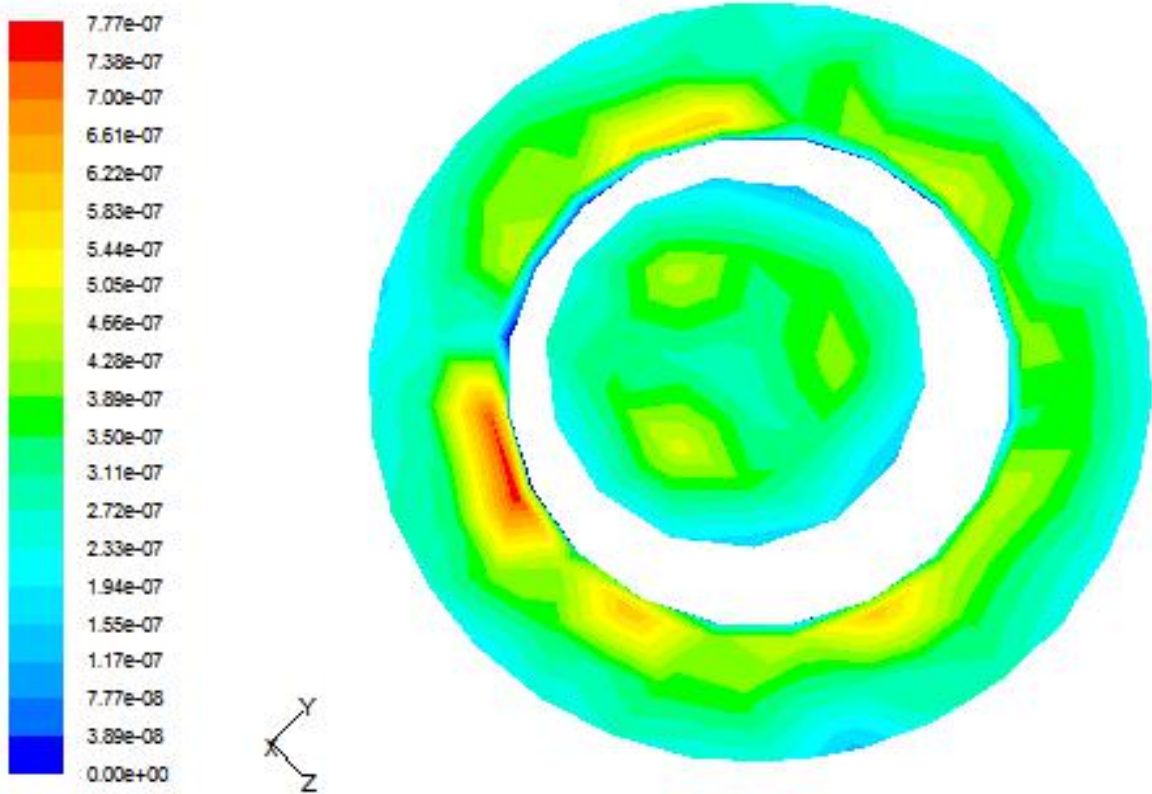

Fig. 7. The wear cloud of the wear-resistant steel plate valve at windward side 

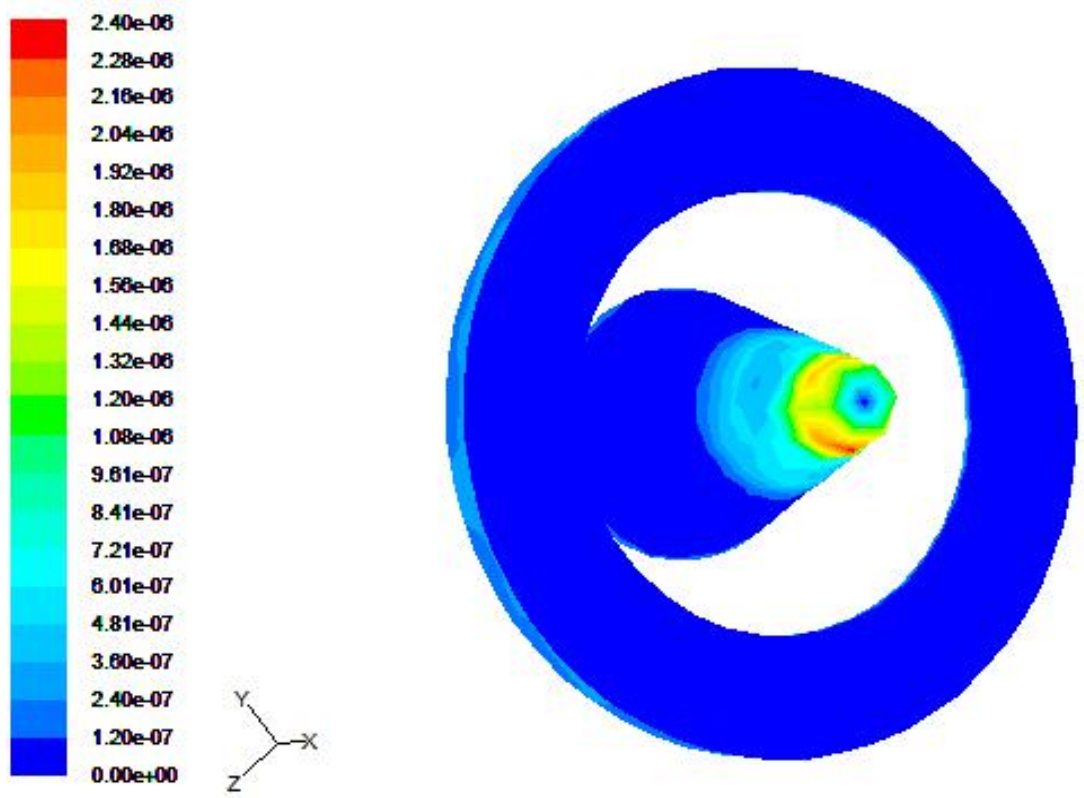

Fig. 8. The wear cloud of the wear-resistant steel plate valve at leeward side

The simulation analysis of wear properties about the wear-resistant ceramic valve

Fig. 9 shows that the abrasion quantity of the value reduces when the ceramic is applied to the value. The maximum abrasion quantity at the windward side is in the edge of the hole plate, it is $3.68 \times 10^{7} \mathrm{~kg} / \mathrm{m}^{2} \cdot \mathrm{s}^{-1}$ and is 1.11 times lower than the abrasion of the steel plate value. It proves that the abrasive resistance of the wear-resistant ceramic valve is obviously superior to the wear-resistant steel plate valve. It puts forward that the abrasive resistance of the valve can be effectively improved if the end face of the hole plate at upwind side uses Wear-resistant ceramic patch and the end face of the value core at upwind side is thickened, its service life can be prolonged and the cost causing by the valve wearing will also reduce.
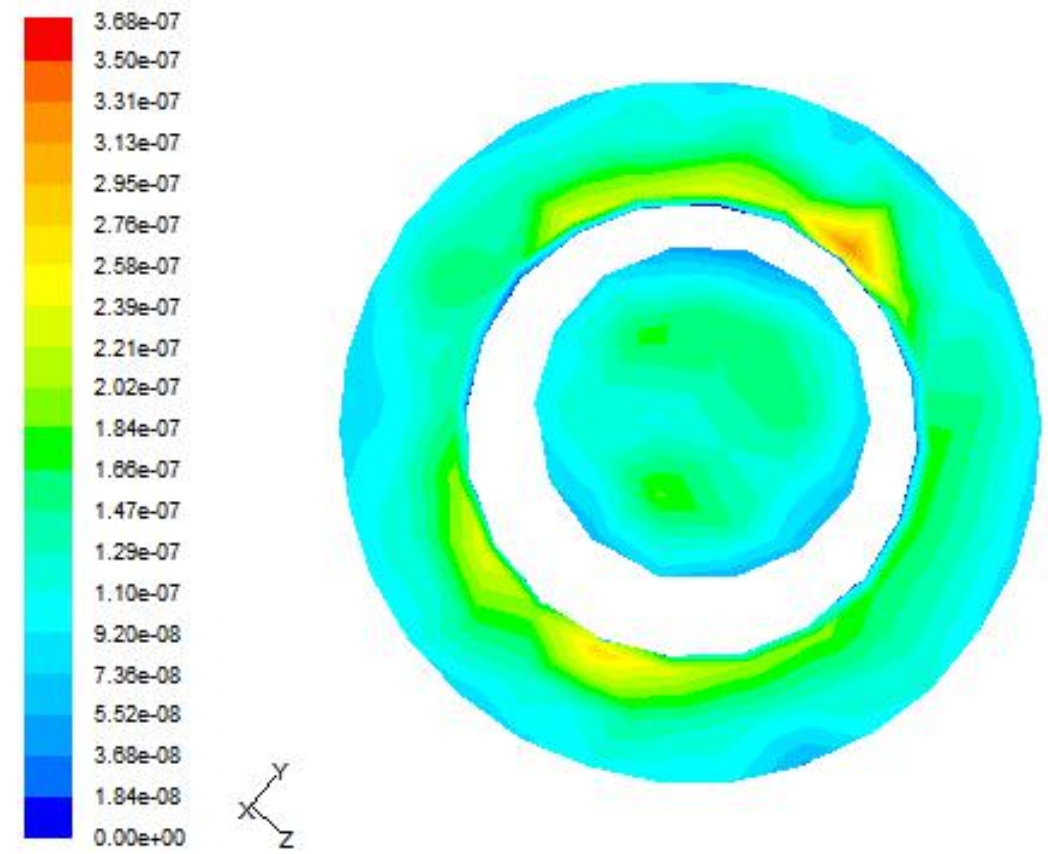

Fig. 9. The wear cloud of the wear-resistant ceramic valve at windward side

\section{The Simulation Of Control System About The Adjustable Wear-Resistant Orifice Plate}

In order to achieve precise control of the dust-removal system, which is a nonlinear system that has multi variable, big timing delay, time-varying volatility and is difficult to stabilize, the fuzzy pid 
control combining the advantages of pid control and fuzzy control is adapted to the adjustable wear-resistant orifice plate of the system [4]. Fig. 10 is the Schematic diagram of the adaptive fuzzy pid control.

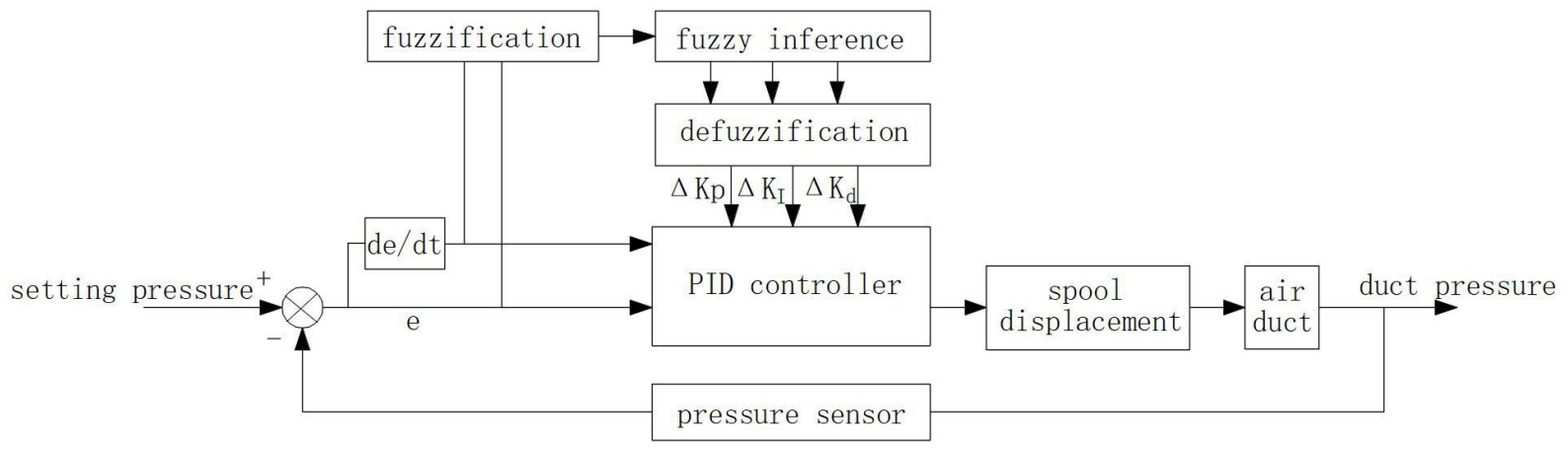

Fig. 10. Schematic diagram of the adaptive fuzzy pid control

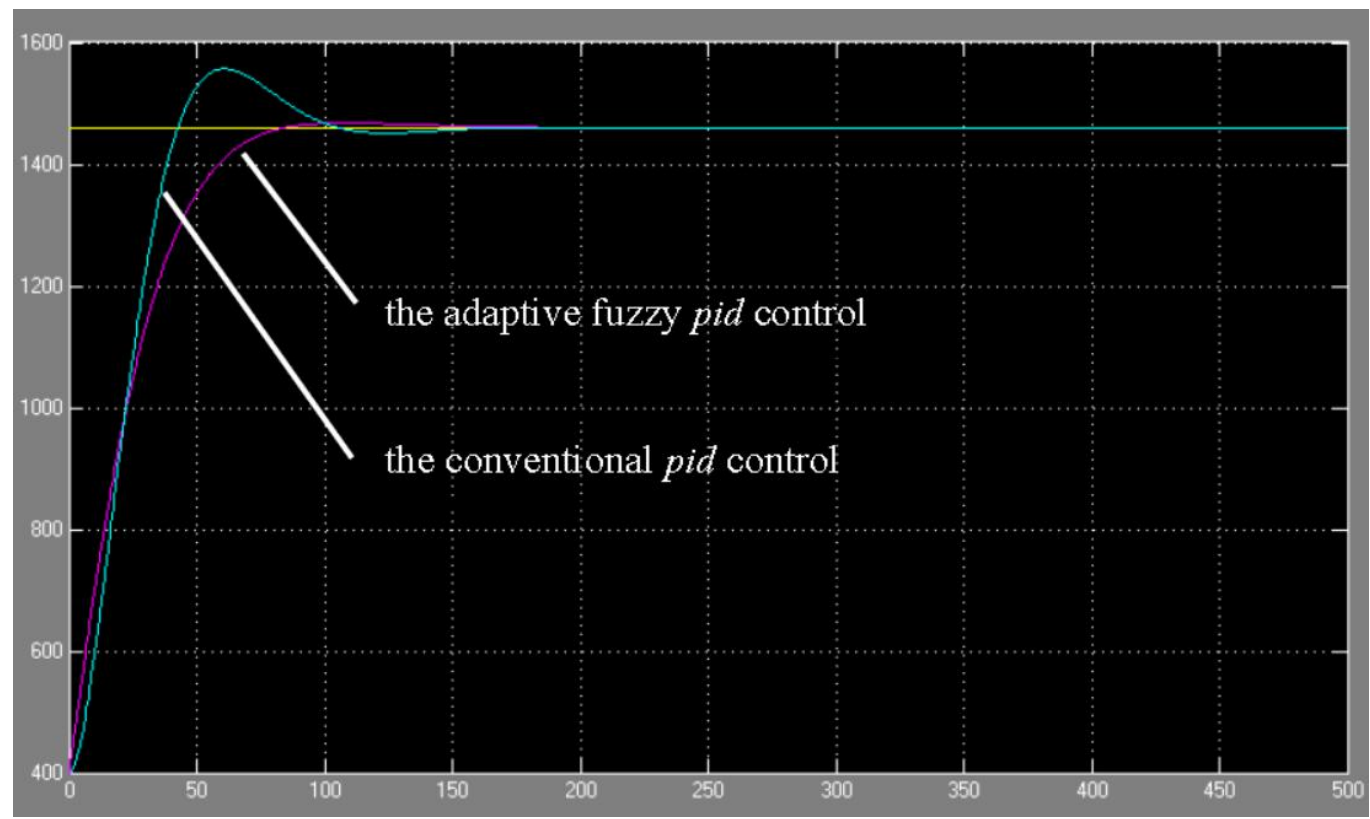

Fig. 11. The simulation of step response about the adaptive fuzzy pid control and the conventional pid control

Fig. 10 is the simulation results of step response about the adaptive fuzzy pid control and the conventional pid control. It can be seen from the figure that the dust-removal system has large overshoot, the oscillation is serious and the adjustment is not timely, when the system's orifice plate adopts the conventional pid control system. On the contrary, if the system's orifice plate adopts the adaptive fuzzy pid control, it responses timely and has smaller overshoot and better stability, its regulating performance is significantly better than the former. Therefore, the system can be adjusted timely and accurately, ensure the dynamic stability and balance of the system resistance and air volume, while the system's orifice plate uses the adaptive fuzzy pid control.

\section{Conclusions}

The following conclusions can be got through the experiment and simulation analysis:

1. The adjustable wear-resistant orifice plate has good regulating performance in balancing the air pressure and stabling the air volume. The local resistance coefficient of the value is linearly proportional to the valve spool's position, it is the value's physical properties and the wind speed has nothing to do with it. Hence, the value can be easily used in engineering system. 
2. The maximum abrasion quantity is in the edge of the hole plate and the end face of the value core at the windward side. Therefore, the abrasive resistance of the valve can be effectively improved if the end face of the hole plate at upwind side uses wear-resistant ceramic patch and the end face of the value core at upwind side is thickened, its service life can also be prolonged.

3. The system can be timely, accurately and steadily controlled when its adjustable wear-resistant orifice plate adopts the adaptive fuzzy pid control. And the resistance disorder the instability of air flow caused by pressure fluctuation can also be eliminated.

\section{References}

[1] Liu Qiuxin, Wu Yuanyuan, Huang Luxia: The Study and Discuss of Some Issue in Dust Removing System of Steel Enterprise (Building Energy \& Environment, China 2005).

[2] Zhang Y, Mclaury B S and Shirazi S A: Improvements of Particle Near-Wall Velocity and Erosion Predictions Using a Commercial CFD Code (Journal of Fluids Engineering, the United States 2009).

[3] Ning Kelin: Analysis of Wearability of Piping for Pulverulent Materials (Modern Metallurgy, China 2001).

[4] Zhang Jingsheng: Research Oil Intelligent Dust Collection System for Coal Making (Hunan University of Science and Technology, China 2013). 